\title{
Tobacco Industry Response to Public Health Concern: A Content Analysis of Cigarette Ads
}

\author{
Kenneth E. Warner, PhD
}

Public awareness of the health hazards of smoking intensified when the subject received national publicity. To assess tobacco industry tactics to counter adverse publicity, we performed a content analysis of cigarette ads in selected issues of Time magazine, for selected years from 1929-84. The analysis showed direct responses to health concerns in all of the years of major smoking-and-health "events," with the possible exception of 1964, the year of the first Surgeon General's report. During these years large percentages of ads emphasized health themes instead of the conventional cigarette ad imagery. On average. health-theme ads have a higher verbal content than the more pictorial traditional ads. Correspondingly, they employ many fewer models. Health-theme ads tend to emphasize the "technological fix," such as the scientifically designed filter and the low-tar cigarette. Subtle changes in cigarette advertising include the elimination of visible smoke from ads.

A decade's concentration on standard health themes, prompted by the "tar wars" of the 1970s. appears to have ended in the 1980s. Advertisers seem to have reverted to the "good times" nonhealth imagery of a bygone era, though possibly to deliver a subtle implicit health message.

Understanding industry advertising tactics can assist public health professionals in developing insights into the promotion of smoking and in formulating smoking control strategies. Though highly exploratory and tentative in nature, this study is offered in the spirit of increasing such understanding.

\section{INTRODUCTION}

The battle between the public health community and the tobacco industry for the hearts and minds (and in the latter instance, wallets) of smokers has been fought on a terrain of publicity and public relations. An integral component of the industry's annual $\$ 1.5$ billion cigarette promotion effort has been an attempt to counteract the market effects of increasingly adverse publicity on the health consequences of smoking. Industry strategy has included at least three tactics:

Kenneth E. Warner is a Professor and Chairman with the Department of Health Planning and Administration, School of Public Health, University of Michigan, Ann Arbor.

This work was supported by a grant from the Josiah Macy, Jr. Foundation and by the W.K. Kellogg Foundation through its National Fellowship Program.

Address reprint requests to Kenneth E. Warner. PhD. Department of Health Planning and Administration. School of Public Health. University of Michigan, Ann Arbor, MI 48109-2029. 
(1) Focusing on nonhealth attributes of smoking. These include the physical characteristics of smoking, such as cigarettes' delivering "flavor" and "satisfaction" and, in the instance of mentholated brands, outdoors "freshness:" and purported social connotations, including sociability, sex appeal and romance, athletic ability, and individuality (rugged manhood and emancipated women).'

(2) Using health concerns to promote so-called "less hazardous" cigarettes. The most direct approach characterized much of the "tar wars" of the early- and mid1970s. For example, a Vantage magazine advertisement portrayed a handsome, sincerelooking male model with the message, "If you smoke and are concerned about your health, switch to Vantage . . . low in tar and you won't sacrifice flavor." An ad for True cigarettes featured a pensive woman attired in tennis gear thinking, "After all I've heard about smoking. I decided to either quit or start smoking True. I started smoking True." Cigarettes such as Carleton and Now have long been promoted as lowest in tar, with the health implication being quite direct.

(3) Market expansion by promoting smoking among women and children. An article in the Louisville Courier Journal quoted a Brown \& Williamson Tobacco Corp. marketing employee as saying, "Nobody is stupid enough to put it in writing or even in words, but there is always the presumption that your marketing approach should contain some element of market expansion, and market expansion in this industry means two things-kids and women. I think that governs the thinking of all the companies."2 Market expansion would be a strategy under any circumstances, but its importance has been increased by the substantial decreases in the proportion of men and teenage boys who smoke.

To develop a better appreciation of the advertising responses of cigarette manufacturers to smoking-and-health concerns, we undertook a content analysis of cigarette ads found in Time magazine from 1929 to 1984. As the nature of the data and analysis are highly exploratory, findings should be construed as merely suggestive. Our principal objective is to heighten health educators" awareness of the "educational" strategies of an industry promoting a product known to be hazardous to health. We are particularly interested in the industry's advertising response to adverse publicity on the health consequences of its product.

\section{METHODS}

Twelve issues of Time (one each month) were selected for study for each of the following years: 1929, 1933, 1938, 1943, 1948, 1951-53, 1957, 1960, 1963-65, $1967-71$. With the number of ads per issue increasing substantially in the 1970s (discussed below), six issues (one every other month) were selected for 1972 and 1973, four issues (one every third month) for 1974-78 and three issues (one every fourth month) for 1979-1983. As data were collected only through early 1984, only two issues were selected for that year.

In each issue, we examined all cigarette ads, recording for each the brand name, whether or not the cigarette was filtered, the cigarette's length, tar category (regular, low, ultra-low), whether or not cigarettes were extracted from packs, whether or not lit, whether or not smoke was present, how the cigarettes were held (hands, mouths, suspended in air), presence (and sex and number) or absence of models, nonhealth themes (e.g., modern design, humor, rugged individualism, sophistication, romance, 
sex appeal, emancipation, femininity, nature, athletics, entertainment, expertise, fame), health theme (extent, from nonexistent to predominant message), and mix of written and pictorial material. The sample totalled 716 ads.

The distribution of each variable was examined across the individual years and groupings of years. Cross-tabs were run across individual and grouped years for several hypothesized relationships (e.g., that health theme would correlate positively with the amount of written, as opposed to pictorial, content of the ad). Years were grouped (and in the 1950s and 1960s, selected) according to their proximity to periods of intense public consideration of the health consequences of smoking. These periods were: 1953-54, the first major lay media discussion of scientific findings linking cancer to smoking; $;^{3-5} 1964$, the year of publication of the first Surgeon General's report on smoking and health; ${ }^{6} 1967-70$, the period of the Fairness Doctrine antismoking messages on television and radio ${ }^{7}$ and the past decade, the era of the nonsmokers' rights movement, punctuated by Joseph Califano's antismoking initiative of 1978 and increased political activity in the early 1980s. The fundamental hypothesis of the study was that the health theme in ads would emerge most strongly during these periods and subside thereafter. The question of interest was how (and if) this would be manifested, and whether (and how) advertisers' approaches to dealing with the health issue would change over time.

Time was selected because it is a widely-read magazine that has been in existence for decades. As a news magazine, Time has a readership that has a higher mean income and education than the national average, yet Time attracts more of a cross section of the population than many other major news weeklies. The former characteristic suggests a readership receptive to and concerned about the smoking-and-health message, while the latter implies a more "typical" response to that message than might be found in a readership consisting predominantly of high income, high education individuals.

The years selected for study included all years since 1967, years of major smokingand-health significance $(1951,1953,1964)$, years immediately preceding (1963), years in between antismoking "events" $(1952,1957,1960,1965)$, and a sampling of years preceding widespread smoking-and-health consciousness $(1929,1933,1938,1943$, 1948).

We do not suggest that the findings of this study are representative of the tobacco industry's advertising response to smoking-and-health publicity and concern. Almost certainly, that response would differ in magazines oriented toward different readerships, including more "upscale" news weeklies, women's magazines, ethnic magazines, and sports magazines. We do believe, however, that Time is the most representative widelyread general circulation magazine accepting cigarette ads* that has published consistently for the half century studied. As such, we believe that this analysis identifies several advertising strategies that have been widely utilized.

We recognize, further, that limitations on ad sample sizes restrict the statistical power of the analysis. The study is offered, therefore, simply as an exploratory examination of how cigarette ad copy has responded to a growing national concern with the health consequences of smoking.

*A magazine whose readership might be considered more representative of the nation is Reader's Digest. The Digest, however, has long had a policy of not accepting cigarette advertisements. 


\section{RESULTS}

Table 1 presents the average number of ads per issue in six groups of years. The groupings here reflect the absence of obvious trends within grouped years and clear differences among groups, in each instance corresponding to a logical change in the social environment for cigarette smoking. The small number of ads for the earliest years reflects a period when there were relatively few branc's of cigarettes, and hence less competition-driven advertising, and a smaller readership of Time. The decade from 1953-63. during which the number of ads per issue doubled, covered the period from the first major smoking-and-health "scare" $3-5$ to just prior to the first Surgeon General's report. 'In only one of the six years between 1929 and 1952 did ads per issue exceed 1.0: in the four years of the second grouping, the number never fell short of 1.25. Increasing competition likely accounts for some of the period-to-period increase, particularly given the then-new growth in smoking by women. ${ }^{\text {. }}$

The six years in the third grouping cover the most intense period of smoking-andhealth publicity, including the Surgeon General's report in 1964 and the Fairness Doctrine broadcast antismoking campaign in 1967-70. Given these factors and the continued growth of smoking among women. the increase in ads per issue of under 40 percent appears relatively modest.

The decade of the 1970s witnessed the most dramatic increases in ads per issue, reflecting increasing competition among the rapidly proliferating number of brands and, especially, the substitution of print for broadcast advertising beginning in 1971 . The latter resulted from the removal of cigarette advertising from the nation's airwaves effective January 2, 1971, the result of the Public Health Cigarette Smoking Act of 1970 (PL 91-2222). ${ }^{4}$ For a few years, the legislation created a forced-savings windfall for the cigarette manufacturers, as their major locus of cigarette promotion was eliminated. Soon thereafter, however, the companies redirected television and radio advertising expenditures to other media, especially the print media. In the first three years following the broadcast ad ban (1971-73), the number of ads per issue of Time more than doubled. For the remainder of the decade and into the early 1980s, the number of ads rose by another three-quarters, averaging 8.28 per issue for 1974-1981. In the most recent years. however. the number (in our small sample) has fallen to $5.28(1982-84)$.

Table 1. Average Number of Cigarette Ads per Issue in Time Magazine,

Selected Years 1929-84. Selected Issues

\begin{tabular}{ccc}
\hline Years & $\begin{array}{c}\text { Average No. Ads } \\
\text { per Issue }\end{array}$ & $\begin{array}{c}\text { \% Increase From } \\
\text { Preceding Period, as } \\
\text { a Percentage }\end{array}$ \\
\hline $1929-52 *$ & 0.78 & - \\
$1953-63$ & 1.54 & +97.4 \\
$1964-70$ & 2.14 & +39.0 \\
$1971-73$ & 4.72 & +120.6 \\
$1974-81$ & 8.28 & +75.4 \\
$1982-84$ & 5.28 & -36.2 \\
\hline
\end{tabular}

*Excludes 1948, an immediate post-War year in which only one ad was found in 12 issues. 
Table 2 presents data on several characteristics of Time cigarette ads for each year examined. Years of major smoking-and-health significance are highlighted. The first two characteristics in the table are objective characteristics of cigarette construction that are perceived as having a high health salience: cigarette filters and low-tar brands. Filter-tipped cigarettes were virtually nonexistant in the $1940 \mathrm{~s}$, as is reflected in the complete lack of ads for filtered cigarettes through 1948. Following scientific studies linking smoking to lung cancer in the late 1940s and lay publicity on the subject in the early $1950 \mathrm{~s}$, filter-tipped cigarettes rapidly claimed a majority market share. In 1952 only 1.3 percent of all manufactured cigarettes had filters. By 1956 the filtertipped market share exceeded a quarter, and only four years later filtered cigarettes became the dominant product on the market. This cigarette consumption revolution was preceded, and encouraged, by a barrage of ads for filtered cigarettes, as seen in the percentage of Time ads for filtered cigarettes in 1951 and the years thereafter. In 1951, when less than 1 percent of all cigarettes sold had filters, eight of the nine cigarette ads in the sampled issues of Time promoted filtered brands. It appears that the intent of the cigarette companies was to convey the message that filters provided protection against the hazardous elements of cigarette smoke responsible for lung cancer. As reflected in the sample, advertisements for unfiltered cigarettes ceased in Time once and for all in 1968, a year in which a quarter of all cigarettes sold were still unfiltered. A decade later, fewer than one cigarette in 10 lacked a filter.

In the 1970s, prompted in part by a well-publicized analysis suggesting that lowtar cigarettes might be "less hazardous," ${ }^{10}$ smokers began to adopt new cigarette brands graded low in tar and nicotine. The cigarette companies quickly turned their promotional efforts toward this new product line, seeing within it the means of encouraging smokers to continue their habits and recruiting new smokers. especially teenage girls and young women: As indicated in our sample of ads (see Table 2), low-tar cigarettes (defined as $15 \mathrm{mg}$ or less of tar) were first advertised in Time in 1967, years before they became a popular commodity. In each year thereafter through 1972, a small proportion of ads ( 12 percent) promoted low-tar brands. This small proportion. however, exceeded the market share of low-tar cigarettes, then only about 5 percent. By 1977, the low-tar market share had risen to close to a quarter; Time ads for low-tar and ultra-low-tar constituted a majority of Time's cigarette ads. Beginning the next year, ads for "regular" (i.e., not low-tar) cigarettes fell to the vicinity of a quarter or less of the total. In 1980, for example, low-tar cigarettes accounted for half of all cigarette sales and 85 percent of Time ads. It is conceivable that the proportion of low-tar cigarette smokers among Time's smoking readership exceeded the national average. It is most unlikely, however, that that proportion closely approached the percentage of ads for low-tar cigarettes in any of these years.

Once a product innovation is established. such as filter tips and low-tar cigarettes, the existence of ads for the product may simply reflect existing consumption patterns, rather than an attempt to steer consumers in new directions. In this context, ads for filter or low-tar cigarettes in the early 1980s can reflect the market without attempting to exploit the health connotations of the product. To assess the industry's direct use of health-related messages, we rated each ad on its health message content. Ratings ranged from 1 (no health content) to 5 (virtually all health message). Column 3 in Table 2 shows the percent of ads in each year that were rated 4 or 5 , predominantly or exclusively health message. Variations in the proportion correspond to variations in the salience of the smoking-and-health issue to the public. Through 1948, no ads 


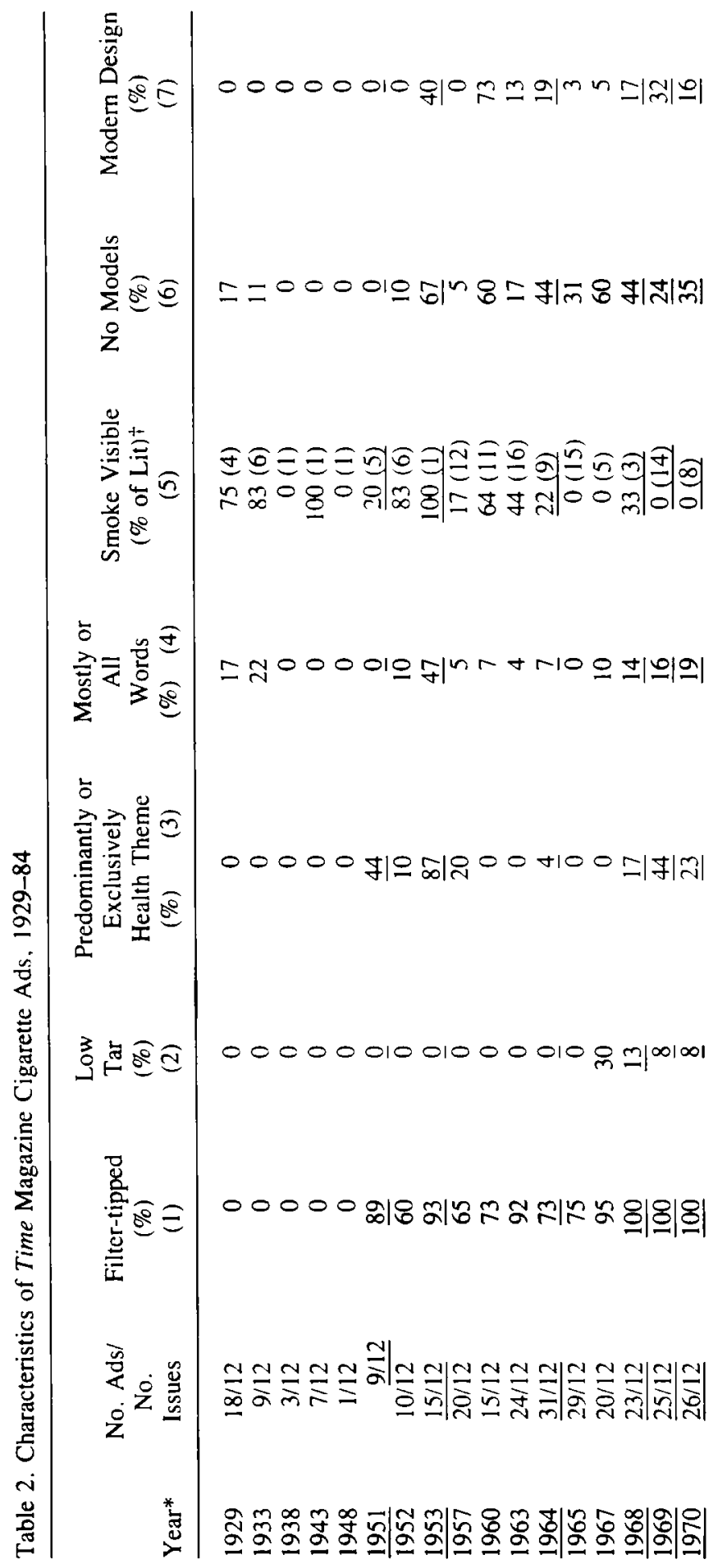




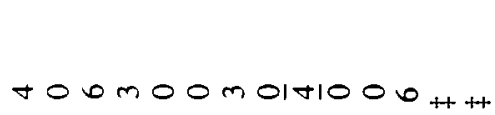

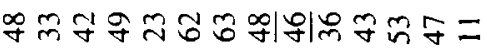

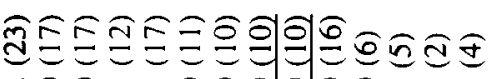
तO $0 x-000100000$

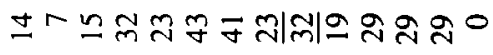

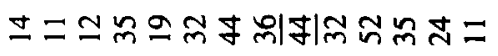

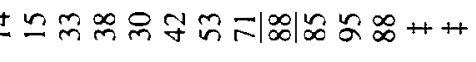

옹ㅇㅇㅇㅇ이이오오오

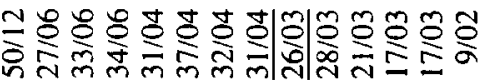

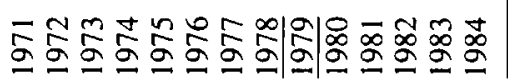

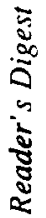

苍蒈

क $\Xi \subseteq$.

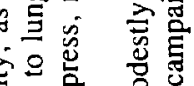

总言

至总 总

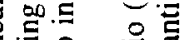

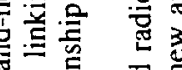

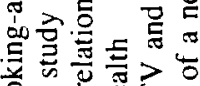

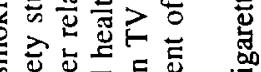

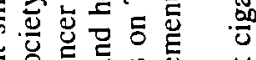

i

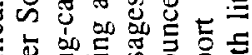

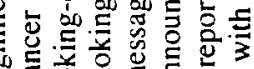

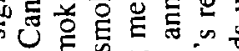

左它

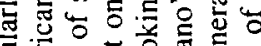

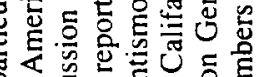

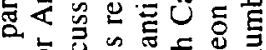

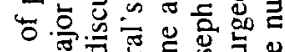

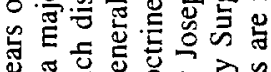

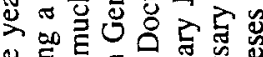

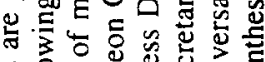

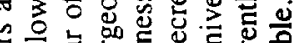

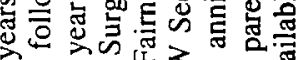

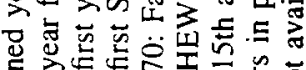

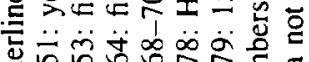

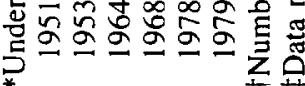


relied heavily on health content. In 1951, however, the year following publicity on a major American Cancer Society study, " 44 percent of the identified ads emphasized a health theme. While the importance of the health message appears to have diminished substantially the next year. in 1953-the year of the first major public smoking-andhealth "scare" "3-5_our health content index achieved its historic high: fully 87 percent of the ads emphasized a health message.

Health as an advertising theme receded in importance for nearly a decade and a half. According to our sample of ads and our measures of ad characteristics, little health theme advertising followed the issuance of the first Surgeon General's report, ${ }^{6}$ commonly identified as the most significant landmark in smoking-and-health history. Other indexes. some noted below, support the finding that the character of advertising in the mid-1960s was not altered substantially in the health direction. It is possible that the cigarette manufacturers were devoting "health-response" efforts to other, nonadvertising efforts. such as the development of low tar and nicotine cigarettes. Nevertheless, the absence of the health-theme advertising makes the mid-1960s the only period when a major smoking-and-health "event" was not associated with clearly "responsive" advertising in Time.

In 1968, 1969, and 1970, ads with a distinct health theme reappeared. These were the three full years of Fairness Doctrine antismoking messages on television and radio, a phenomenon that had a significant impact on smoking behavior and attitudes toward smoking. ${ }^{7}$ With the removal of cigarette ads from the broadcast meciia in 1971, the donated Fairness Doctrine messages disappeared as well, and so did the health theme in the vast majority of sampled ads in Time.

The health theme reemerged in 1974 and remained strong through 1982. This time period corresponded to the development of a strong nonsmokers' rights movement, with the locus of smoking-and-health activity having shifted from the national to state and local level. In 1983 and particularly in 1984, however, the index of health theme fell to its lowest level in over a decade. Other indexes support the finding that cigarette advertising. as reflected in Time magazine as of early 1984, has "retrenched" to its standard nonhealth themes.

A correlate of the health theme variable is an index of the pictorial versus verbal content of ads. In this rating, ads were scored from 1 to 4, corresponding, respectively, to mostly picture (e.g., Marlboro ads), mixed, mostly words, and virtually all words (e.g., Carleton ads). As column 4 in Table 2 shows, the largest annual fractions of ads relying primarily on verbal presentations occurred during periods of smoking-andhealth concern, with the largest proportion, nearly half, found in 1953. The fractions during 1968-70 were slightly larger than those of the surrounding years, but a sustained emphasis on the verbal image began along with the nonsmokers' rights movement in the mid-1970s. Again, it is noteworthy that 1964 ads exhibited no trenci toward the verbal mode, and of the ads examined in 1984, not one fell into the categories of mostly or all words.

A most interesting characteristic of cigarette advertising in the print media has been the virtual disappearance of visible smoke from advertisements in which cigarettes are clearly lit. Column 5 gives the percentage of ads with lit cigarettes in which smoke is present. While smoke is present in many ads (50 percent) prior to the year of the Surgeon General's report, from 1964 on only a small fraction ( 5 percent) of lit cigarettes emit visible smoke. The fraction was relatively large in 1964 (22 percent), but the 
drop to zero the next year may represent a subtle response to the Surgeon General's report and its attendant publicity. From 1976 on we did not find a single instance of smoke being visible in the sampled ads. While in the early years smoke connoted an attractive, even seductive image, for the past two decades cigarette advertisers have considered smoke sufficiently undesirable as to air-brush it out of their ads. It must be noted, however, that while our small sample of 1984 ads did not reveal any with smoke, we have seen recent ads in which the smoke is visible. This is consistent with other recent changes in apparent advertising strategies, as we discuss in the next section.

Both friend and foe of the tobacco industry acknowledge the industry's effective use of models in cigarette ads. Models typically are used to present an image that the manufacturers would like the public to associate with smoking, such as youthfulness, sexual attractiveness, sophistication, or athletic ability. It is not surprising, therefore, that at times when the industry feels the need to respond directly to smoking-andhealth publicity, it relies less heavily on the use of models. Column 6, which gives the percentage of ads in each year having no models, shows that models were present in almost all of the ads published prior to 1953. In that seminal smoking-and-health year, however, two-thirds of the sampled Time ads had no models. The numbers for the next three years in the sample fluctuate widely, but the year of the first Surgeon General's report, 1964, initiated a period of close to two decades in which a quarter to a third and even a half of all ads did not use models. This is another example of a subtle advertising response to the Surgeon General's report. The "tar wars" era from the mid-1970s to the early-1980s saw the greatest concentration of no-model ads. Again, however, it is noteworthy that in our small sample of 1984 ads ( $n=9$ ), only one did not utilize a model. The resultant percentage, 11 percent, was the lowest proportion of no-model ads since 1957.

Certain advertising strategies have been unique to a given smoking-and-health "era." The just-mentioned "tar wars" was the phenomenon of the past decade. A related if dated theme was what we call "modern design," an emphasis on the "technology" of the filtration system. In the 1950 s and, to a lesser extent, the $1960 \mathrm{~s}$, cigarette brands such as Kent (Micronite filter), Parliament (recessed filter), Tareyton and L.ark (charcoal filtration) emphasized the unique designs of their filtration systems, conveying the idea that the systems somehow reduced the hazards of smoking or improved the pleasures. Column 7 shows the percentage of ads we identified as having a modern design theme. As the data indicate, this approach to promoting the "safety" of cigarette brands largely disappeared after the era of the Fairness Doctrine messages. $\dagger$

As the data in Table 2 suggest, there are a number of correlations between ad images and health-connotation strategies. Rather than develop these in detail here, we simply note a few relationships that are statistically significant by a chi-square test applied to contingency tables set up for grouped years (similar groupings to those discussed for the average number of ads per issue; see Table 1). Extent of health theme is strongly correlated with the verbal content of ads. That is, ads having a disproportionate emphasis on words, rather than pictorial images, tend to be trying to convey a health message. Such ads are directed to the health-conscious smoker whom the companies

fOne could argue that the low-tar advertising theme is an extension of the modern design theme. The distinction is that the latter emphasized cigarette filter construction while the former emphasizes "outcome," typically with little discussion of the mechanism by which it is achieved. 
recognize they may lose if they cannot convince the smoker that their products are truly "less hazardous." By contrast, ads with a heavy reliance on visual imagery (active models, beautiful scenery, etc.) have deemphasized health themes.

The extent of health theme is also correlated, inversely, with the number of models in ads. The major differentiation is between ads with no models (typically health theme) and those with one or more models (typically nonhealth theme). One also finds that ads with health themes and models tend to have only one model, as in the Vantage and True ads mentioned at the beginning of this article. It is not the case, however, that ads with only one model tend to have health themes. The majority are selling conventional nonhealth images, such as rugged individualism.

It would seem obvious that ads for low-tar cigarettes should show a high correlation with health themes. This is the case for most of the era studied, but in 1984 the correlation is not found: 1984 ads do promote low-tar cigarettes, which claim the majority of the market; but the health theme is absent. The low-tar ad of 1984 employs the same imagery and attempts to connote the same associations as the nonhealththeme ad for regular cigarettes two decades ago.

\section{DISCUSSION}

By a number of measures, the national antismoking campaign has been successful in discouraging the initiation and continuation of smoking. ${ }^{12}$ Cigarette ads appear to have been effective for years in promoting smoking. ${ }^{1.13}$ The manufacturers' advertising responses to adverse publicity on the health consequences of smoking almost certainly have been effective in diminishing the impact of this publicity. A notable example has been the successful campaign promoting low-tar cigarettes, which grew in popularity from 5 percent of the market in the early 1970s to 60 percent a decade later. Supported by direct and indirect government "endorsement" of low-tar cigarettes for the smoker who cannot or will not quit, this advertising campaign has succeeded in boosting national cigarette consumption compared to what it would have been, by at least three mechanisms: retaining in the smoking population people who might otherwise have quit; causing many smokers to increase their daily cigarette consumption to compensate for the reduced nicotine yield of low-tar cigarettes $;{ }^{14}$ and possibly "making it easier" for young nonsmokers, particularly teenage girls, to start smoking. ${ }^{15}$ Recent evidence suggests that the potential health benefits of smokers' switching from regular to low-tar cigarettes are minimal. ${ }^{16-18}$ Yet much of the public has been sold on the notion that the new product is less hazardous and possibly even "safe." A 1980 national survey, for example, found one-third of the respondents knowing or thinking it was true that "it has been proven that smoking low-tar, low-nicotine cigarettes does not significantly increase a person's risk of disease over that of a nonsmoker." An additional third of the sample responded that they did not know whether or not the statement was true.'

The sample of Time ads used in this study - a total of 716-may not have been sufficient to provide a statistically representative sample of cigarette ads placed in Time in each year studied. It was, however, large enough to suggest several trends and techniques employed in cigarette ads to combat adverse publicity on the health consequences of smoking. From the sample we see that through their ads the cigarette 
companies "talk" with consumers about the health issue, but only when "necessary" (i.e., to counter visible adverse publicity). Visually attractive nonhealth images yield to a "discussion" format. We see further that the "technological fix"-the scientifically designed filter, the low-tar cigarette-is a standard industry response.

These approaches are clear and direct. Others are not. Witness, for example, the removal of smoke from cigarette ads, a previously appealing element that has become an unesthetic feature of smoking. While not an enormously subtle advertising innovation, it is sufficiently so that even many readers of this journal may not have noticed it consciously. Much more subtle are subliminal messages, such as camouflaging the word "sex" on the bodies of attractive models. ${ }^{19}$

This study indicates variations in the intensity of the industry's responses to different smoking-and-health "scares." The response to the publicity in the early 1950s appears to have been swift and substantial. By contrast, the landmark Surgeon General's report, which is credited with reducing adult per capita cigarette consumption by almost 5 percent in $1964,{ }^{20}$ does not appear to have provoked a significant immediate change in industry advertising strategy. This is perhaps the greatest anomaly of the study. The period of the Faimess Doctrine broadcast messages saw a resumption of industry response, though not as strong as that of 1953. The "tar wars" of the 1970s represented the most sustained industry reaction to public concern about smoking. The persistence of the "wars," however, likely resulted not from antismoking publicity response per $s e$, but rather from recognition of the market maintenance and growth potential of low-tar cigarettes.

Our small sample of 1984 ads, plus casual observation, suggests that the era of the tar wars may have ended. The Time ads sampled for 1984 reveal a sales strategy not unlike that which preceded public concern about the health effects of smoking. The scenes are from the ' $80 \mathrm{~s}$ as is the product, but the themes are from the " $40 \mathrm{~s}$ : glamour, success, sexual attraction, and sociability are back in; the explicit health theme appears to be out. Preceding this reversion to earlier imagery, the low-tar share of the market fell slightly in each of 1982 and 1983, the first decreases in the low-tar percentage since low-tar cigarettes were introduced. ${ }^{21}$ The most likely explanation for these decreases is continuing reductions in the light-smoker population, including less initiation of smoking by teenagers. An optimistic reading of the apparent new advertising strategy is that for the first time the industry may be directing much of its promotional effort solely to the role it has long claimed for cigarette advertising: competing for market shares of a fixed pie (i.e., current confirmed smokers). Alternatively, industry advertising directors may have concluded that the most effective contemporary response to health concerns is an indirect one: conveying visual images of vibrant, physically fit, successful, sociable, and sexy people in physically active or glamorous settings, in other words, associating smoking with people who are the proverbial "picture of health."

Understanding cigarette advertising tactics can help the public health community to acquire insight into the determinants of smoking, as these are understood by tobacco industry marketing specialists who have had access to substantial market research funding and proprietary data. Such insight can be applied indirectly, in developing a knowledge base for counseling smokers or educating youngsters (e.g., the concept of "immunizing" children against cigarette ads); or it can be applied directly, as in parodies of cigarette ads produced by such organizations as the American Heart Association 
and DOC (Doctors Ought to Care). As an advertising executive has observed, there is no reason that nonsmoking cannot be sold as effectively as smoking. The success of the amaturish Fairness Doctrine smoking-and-health messages suggests that wellresearched and professionally prepared counter-advertising could have a substantial impact. ${ }^{22}$ The major problem in this regard is that the resources available to promote the nonsmoking message - and hence the public's exposure to the message - can never hope to compete with the tobacco industry's annual investment of $\$ 1.5$ billion in promoting its product.

This study has focused only on direct advertising responses to public concern about the health effects of smoking. Not considered here have been advertising tactics developed for market expansion, particularly those directed at women. ${ }^{2.3}$ As the traditional male-oriented market continues to diminish. attempts to recruit women into the smoking population will be of continuing importance to the industry. Developing understanding of the industry's advertising tactics will help concerned health professionals to fight fire with fire, but without smoke.

I am grateful to Julian Epstein and Jane Somers for research assistance and to two anonymous reviewers for helpful suggestions.

\section{REFERENCES}

1. Myers ML, Iscoe C. Jennings C, et al: Staff Report on the Cigarette Advertising Investigation. Washington, DC, Federal Trade Commission, 1981.

2. Pertschuk M: Statement on FTC endorsement of rotational health warnings legislation and additional cigarette advertising issues. Washington. DC. Federal Trade Commission, May 3, 1984.

3. Norr R: Cancer by the carton. Reader's Digest 61 (December):7-8, 1952.

4. Lieb C: Can the poisons in cigarettes be avoided? Reader's Digest 63 (December):45-47, 1953.

5. Miller L. Monahan J: The facts behind the cigarette controversy. Reader's Digest 65 (July):1-6, 1954.

6. U.S. Department of Health. Education, and Welfare. Public Health Service: Smoking and Health: Report of the Advisory Committee to the Surgeon General of the Public Health Service. Washington, DC, Govemment Printing Office. 1964.

7. Warner KE: Clearing the airwaves: The cigarette ad ban revisited. Policy Analysis 5:435-450, 1979.

8. Harris JE: Cigarette smoking among successive birth cohorts of men and women in the United States during 1900-80. JNCI 71:473-479, 1983.

9. Friedman KM: Public Policy and the Smoking-Health Controversy. Lexington, MA, DC Heath, 1975.

10. Gori GB. Lynch CJ: Toward less hazardous cigarettes. JAMA 240:1255-1259. 1978.

11. Wynder EL, Graham EA: Tobacco smoking as a possible etiologic factor in bronchiogenic carcinoma. A study of six hundred and eighty-four proved cases. JAMA 143:329-336, 1950

12. Warner KE: The effects of publicity and policy on smoking and health. Business \& Health 2:7-13, November 1984.

13. Foote E: Advertising and tobacco. JAMA 245:1667-1668, 1981.

14. Gerstein DR, Levison PK (eds): Reduced Tar and Nicotine Cigarettes: Smoking Behavior and Health. Washington, DC. National Academy Press, 1982.

15. Harris JE: Public policy issues in the promotion of less hazardous cigarettes, in Gori GB, Bock FG (eds): Banbury Report 3. A Safe Cigarette? Cold Spring Harbor, NY. Cold Spring Harbor Laboratory, 1980.

16. Russell MAH, Jarvis $M$, Iyer $R$, et al: Relation of nicotine yield of cigarettes to blood nicotine concentrations in smokers. Br Med J 6219:972-976, 1980.

17. Benowitz NL. Hall SM. Herning RI, et al: Smokers of low-yield cigarettes do not consume less nicotine. N Engl J Med 309:139-142, 1983.

18. Folsom AR. Pechacek TF, deGaudemaris R, et al: Consumption of "low-yield" cigarettes: Its frequency and relationship to serum thiocyanate. Am J Public Healih 74:564-568, 1984.

19. Key WB: Subliminal Seduction. Englewood Cliffs, NJ: Prentice Hall, 1973.

20. Wamer KE: Cigarette smoking in the 1970's: The impact of the antismoking campaign on consumption. Science 211:729-731, 1981. 
21. U.S. Department of Agriculture, Economic Research Service: Tobacco Outlook and Situation Report. March 1984. TS-187.

22. Green P: The mass media anti-smoking campaign around the world, in Steinfeld J, Griffiths W, Ball $\mathrm{K}$, et al (eds): Proceedings/3rd World Conference on Smoking \& Health. Washington, DC. Public Health Service, DHEW Pub No (NIH)77-1413. 1977

23. Emster VL: Selling cigarettes: How women are used. in Nostbakken D (ed): Proceedings of the Sth World Conference on Smoking and Health (forthcoming). 